San Jose State University

SJSU ScholarWorks

Master's Projects

Master's Theses and Graduate Research

$8-7-2000$

\title{
Perceived Barriers by Hispanic Mothers in Obtaining Primary Health Care for Their Childern
}

Michael Allen Hart

San Jose State University

Follow this and additional works at: https://scholarworks.sjsu.edu/etd_projects

Part of the Family Practice Nursing Commons, and the Pediatric Nursing Commons

\section{Recommended Citation}

Hart, Michael Allen, "Perceived Barriers by Hispanic Mothers in Obtaining Primary Health Care for Their Childern" (2000). Master's Projects. 857.

DOI: https://doi.org/10.31979/etd.wc2y-v8zf

https://scholarworks.sjsu.edu/etd_projects/857

This Master's Project is brought to you for free and open access by the Master's Theses and Graduate Research at SJSU ScholarWorks. It has been accepted for inclusion in Master's Projects by an authorized administrator of SJSU ScholarWorks. For more information, please contact scholarworks@sjsu.edu. 


\section{SAN JOSE STATE UNIVERSITY SCHOOL OF NURSING}

\section{MASTER'S PROGRAM PROJECT OPTION (PLAN B) PROJECT SIGNATURE FORM}

STUDENT NAME

MichaeL

A HART

SEMESTER ENROLLED Summer 2000

TITLE OF PROJECT Percelved Barriers by HISPANic Mothers in ODTIANINS Primary HeAlth CARe for their ChIdrew

NAME OF JOURNAL JOURNAL OF TRANSCUTURAL NURSINS

The project and manuscript have been successfully completed and meet the standards of the School of Nursing at San Jose State University. The project demonstrates the application of professional knowledge, clinical expertise, and scholarly thinking. An abstract of the project and two copies of the manuscript are attached.

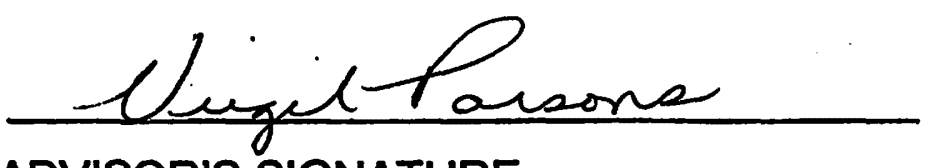

ADVISOR'S SIGNATURE

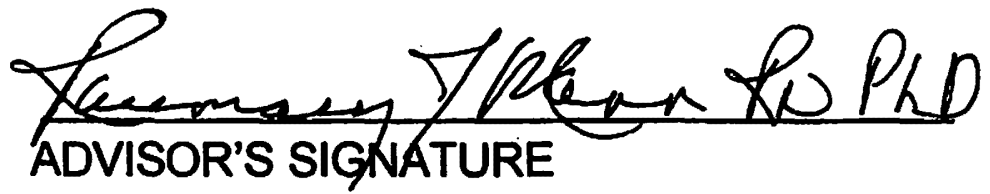

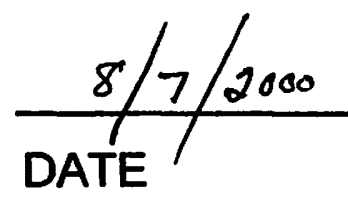

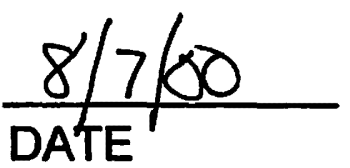

Please submit this form to the Graduate Coordinator. Attach abstract, two copies of the manuscript, and documentation of submission to the journal (i.e., postal receipt). 


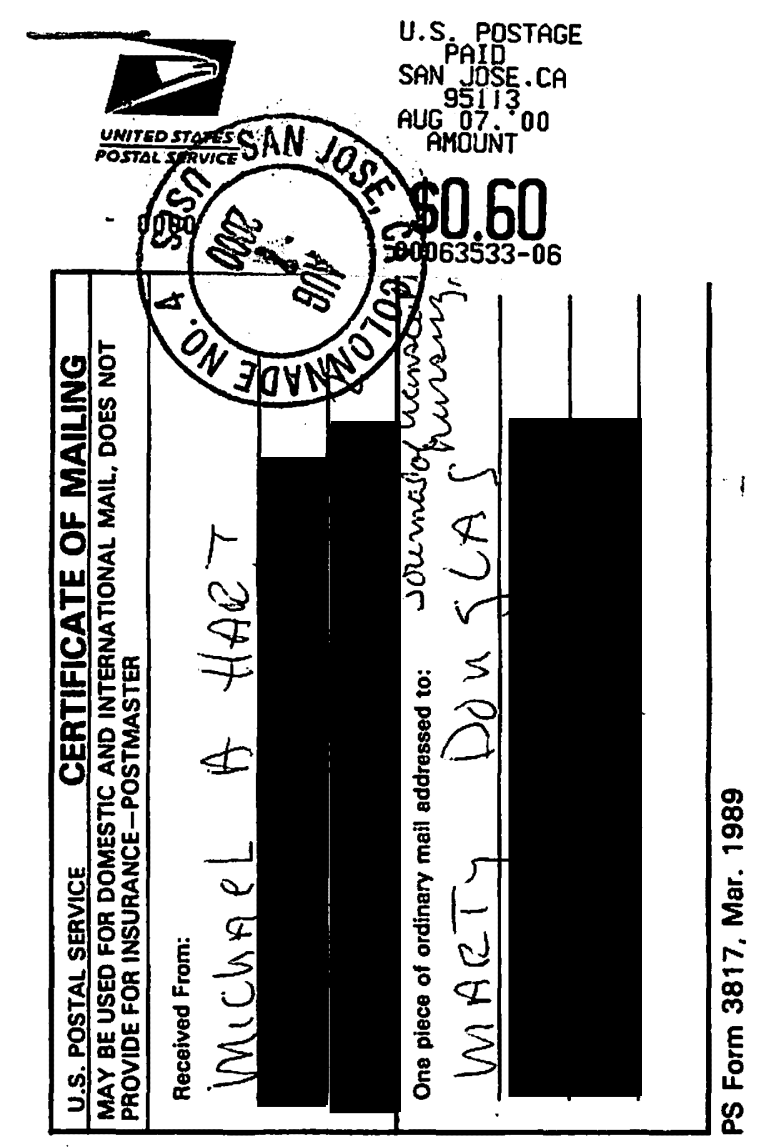

\begin{tabular}{|c|c|c|c|}
\hline $08 / 07 / 2000$ & & & $03: 18: 04 \mathrm{PI}$ \\
\hline $\begin{array}{l}\text { Product } \\
\text { Description }\end{array}$ & $\begin{array}{l}\text { Salos } \\
\text { Sale } \\
\text { Qty }\end{array}$ & $\begin{array}{l}\text { Recelpt } \\
\text { Unit } \\
\text { Price } \\
\end{array}$ & $\begin{array}{l}\text { Final } \\
\text { Price }\end{array}$ \\
\hline \multirow{2}{*}{$\begin{array}{l}94306 \text { Priority } \\
\text { values }\end{array}$} & lbest & & $\$ 3.20$ \\
\hline & Issue & PVI: & $\$ 3.20$ \\
\hline \multirow{2}{*}{$\begin{array}{l}\text { Single } \\
\text { Certificate } \\
\$ 6.60 \text { City } \\
\text { Flag PSA BK }\end{array}$} & 1 & $\$ 0.60$ & $\$ 0.60$ \\
\hline & 1 & $\$ 6.60$ & $\$ 6.60$ \\
\hline \multicolumn{3}{|l|}{ Total: } & $\$ 10.40$ \\
\hline \multicolumn{3}{|l|}{$\begin{array}{l}\text { Pald by: } \\
\text { Cash } \\
\text { Change Due: }\end{array}$} & $\begin{array}{r}\$ 20.50 \\
-\$ 10.10\end{array}$ \\
\hline & & & \\
\hline \multicolumn{3}{|c|}{$\begin{array}{ll}\text { Bill\#: } & 1000200053709 \\
\text { Clerk: } & 06\end{array}$} & \\
\hline
\end{tabular}




\begin{abstract}
Purpose: Hispanic mothers tend to over use hospital emergency services and under use primary care providers when seeking health care for their children. . In order to change this health care utilization behavior, researchers must understand the barriers to health care perceived by Hispanic mothers.

Design: In this non-experimental survey study, a non-probability, purposive sampling of 45 Hispanic mothers at a rural county pediatric clinic were surveyed.

Methods: Using the Health Belief Model (HBM) as its framework an 18-item survey examined, barriers to health care, cues to action, subjects' knowledge, family satisfaction, access, and likelihood of action.

Findings: The data suggest that long waiting periods for clinical appointments, limited clinical hours, and lengthy waiting room delays are the major perceived barriers by these Hispanic mothers.
\end{abstract}


Running head: Perceived Barriers by Hispanic Mothers in Obtaining Health Care.

\author{
Perceived Barriers by \\ Hispanic Mothers in Obtaining \\ Primary Health Care for Their Children
}

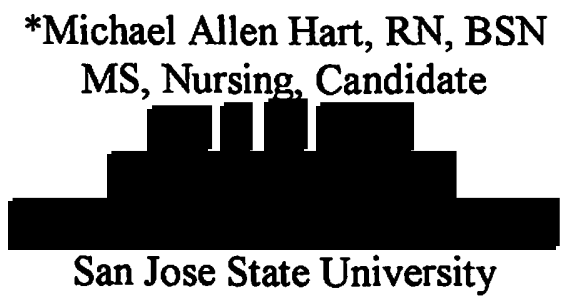

\title{
Virgil Parsons, DNSc, RN \\ School of Nursing \\ San Jose State University
}

Rosemary J. Mann RN, JD, PhD

School of Nursing

San Jose State University. 


\begin{abstract}
Purpose: Hispanic mothers tend to over use hospital emergency services and under use primary care providers when seeking health care for their children. . In order to change this health care utilization behavior, researchers must understand the barriers to health care perceived by Hispanic mothers.

Design: In this non-experimental survey study, a non-probability, purposive sampling of 45 Hispanic mothers at a rural county pediatric clinic were surveyed.

Methods: Using the Health Belief Model (HBM) as its framework an 18-item survey examined, barriers to health care, cues to action, subjects' knowledge, family satisfaction, access, and likelihood of action.

Findings: The data suggest that long waiting periods for clinical appointments, limited clinical hours, and lengthy waiting room delays are the major perceived barriers by these Hispanic mothers.
\end{abstract}




\section{Problem}

An estimated 39 million Hispanics live in the United States (US) representing 15\% of the total national population. The average age of US Hispanics is 26 years old. In the US, 12 million children, one out of nine, are of Hispanic origin. Approximately $31 \%$ of Hispanic children with working parents lack medical insurance as compared to $12 \%$ of the nonminority children in this country. Many Hispanic children live in poverty, $40 \%$ more than any other minority in this country (U.S. Department of Health and Human Services, 1999).

Due to the influx of new refugees and immigrants into the United States, the health care system has been compelled to deliver services to an increasingly under-insured population. It is estimated that 1.5 million documented and 1 million undocumented foreign-born nationals enter this country every year (Haggerty, 1995). Research indicates that low-income Hispanic populations tend to under-use health care services and may not have a regular primary care provider. Because of barriers to accessing health care, Hispanic mothers tend to use hospital emergency services for their children instead of a primary provider (Zambrana, Ell, Dorrington, Wachsman, \& Hodge, 1994).

Nine years of the researcher's personal experience in a hospital emergency department (ED) serving a large Hispanic population have indicated that a large percentage of ED visits were for non-emergency pediatric patients. A majority of these ED visits were for otitis media, pharyngitis, laryngitis, allergic rhinitis, upper respiratory infection, nausea, and vomiting of a non-emergency nature. These visits occurred in spite of a modern full service county pediatric clinic based less than 5 miles from the ED. A physician at the local county clinic stated that the clinic providers averaged only about 2.5 patients per hour each, indicating that the clinic was under-used (Dr. Elizabeth Mendoza-Levy, personal communication, November 2, 1999). 
Dr. Mendoza-Levy also related that the clinic has a $35 \%$ no-show rate for scheduled appointments and $50 \%$ of the all the patients seen are walk-in's. Dr. Mendoza-Levy describes the lack of access to phones as an important factor in this high no-show rate making it difficult for patients to get their appointment reminder calls. Without phone access, making an appointment can be challenging, so patients just show up hoping for an opening.

This personal experience and information led to questioning why a population would choose to use a hospital ED for dealing with common, non-emergency ailments when a modern and efficient county pediatric facility is in the same area. Are there barriers for these Hispanic mothers when obtaining primary care for their children in a clinic rather than an emergency room?

\section{Research Question}

The under-utilization of the modern county clinic and over-utilization of the hospital ED for non-emergency illness is clearly an inefficient and nonproductive pattern. In order to change the utilization behavior, researchers must understand the perceived barriers by Hispanic mothers in obtaining health care. The question this research study asked is: What are the barriers perceived by Hispanic mothers in one California county health care facility in obtaining primary health care for their children?

\section{Theoretical Framework}

In the early 1950 s, the primary function of Public Health Service (PHS) was prevention. Medical care and treatment of diseases were not the foci. Investigators for the PHS, under the influence of Kurt Lewin, became interested in the widespread failure of people to accept free or very low cost preventive and screening tests for tuberculosis. Godfrey Hochbaum, Stephen Kegels, and Irwin Rosenstock, who were trained in social psychology with a phenomenological orientation, 
developed the Health Belief Model (HBM) to help explain this phenomenon (McCormack-Brown, 1999).

The HBM (Appendix A) has long been used as a conceptual formulation for understanding why individual populations do or do not engage in a variety of health-related actions. The usefulness of the HBM in understanding health related decision making is well-documented (Janz \& Becker, 1984). The HBM assesses the potential negative aspects of taking a recommended health action against the perceived positive gain of good health.

The HBM states that, before an individual takes action, he or she must decide (a) that a problem behavior creates a serious health problem, (b) that he or she is susceptible to health harm, and (c) that modifying the behavior will have beneficial results. Researchers have used the HBM to explain different preventive health care actions, such as sick role and clinic utilization behaviors (Janz \& Becker, 1984). Rosenstock (1974) indicated that the combination of the individual's perception of susceptibility and severity of health harm provides the energy for action in the HBM. The perception of high benefits and low perceived barriers provide the direction of action within the model.

Perceived threats of disease and demographic, socio-psychological, and structural variables are important modifying factors in the HBM. These variables tend to condition perceptions and perceived benefits of preventive actions in individuals (Rosenstock, 1974). The specific constructs of the HBM are (a) perceived susceptibility to a disease or health problem, (b) perceived seriousness of the disease or health problem, (c) perceived benefits of preventative actions, (d) perceived barriers to undertaking a new behavior, (e) perceived self-efficacy, and (f) influencing cues to action (Strecher \& Rosenstock, 1997). 


\section{Literature Review}

Zambrana et al. (1994) studied the psychosocial status of immigrant Latino mothers and their use of pediatric emergency services for their children in Los Angeles County. The five most commonly perceived barriers to health care in this study were (a) too long a wait in the clinic, (b) too long to wait for an appointment, (c) the cost of care, (d) the staff not speaking Spanish, (e) the lack of Latino staff, and (f) the lack of confidence in health care staff. The authors of this study found that perceived barriers to care and mental stress of the mothers resulted in a clear pattern of delayed care for acute problems in the pediatric patients.

Of the mothers $(n=80)$ in this study's sample, $36 \%$ related that the hospital ED was their usual site of primary care for their children. It was postulated that these Hispanic mothers might perceive the hospital ED site to be more available and accessible then other health care options. Psychosocial health status and the inability to manage everyday tasks related to mental distress might influence a mother's health care decisions (Zambrana et al., 1994). Zambrana et al. (1994) also suggested that racism and discrimination are endemic in the delivery, administration, and planning of health care services. These barriers impeded the ability of the Hispanic family to access primary care for themselves and their children. The psychosocial theoretical perspective that Zambrana et al. (1994) used in assessing their Hispanic mothers was multi-disciplinary. Portions of their research tool used the HBM to measure (a) mother's overall assessment of her child's health, (b) perception of the seriousness of current symptoms, and (c) perceived barriers to health care services.

Chan, Krishel, Bramwell, and Clark (1996) examined the health seeking behaviors of undocumented Hispanic immigrants at a San Diego university hospital. They observed that many undocumented persons used the hospital ED as their main and often only source of primary and nonemergency health care. Reasons for hospital ED use were cited as (a) lack of health insurance, (b) restriction of state supported medical coverage to ED visits only, (c) need for specialized care, (d) 
perception that they would receive better care, (e) recommendations from others, and (f) difficulty in obtaining other primary health care because of their undocumented status.

A lack of knowledge of how to access the health care system, language differences, and cultural factors were identified as major barriers for this population. Many of these undocumented immigrants simply did not know of any other available source of health care and $40 \%$ believed no alternative to the hospital ED was acceptable (Chan et al., 1996). Both undocumented and documented Hispanic immigrants in this study were less likely to access pre-hospital care services and use ambulances to arrive at the hospital ED than non-Hispanic patients. This is notable in that undocumented Hispanics had a higher percentage rate than other minority groups of admissions from the ED to the hospital in this study. The authors concluded that a better understanding of the undocumented Hispanic immigrants' health care behaviors is important to future planning and implementation of health care programs. Goals of cost containment and universal coverage may never be met if this growing and vulnerable population is not considered (Chan et al., 1996).

Tyrance, Himmelstein, and Woolhandler (1996) examined the perception of over-use of the hospital ED by uninsured minorities and its effect on the rise of health care costs. The authors analyzed ED visits by minorities such as the elderly, low-income families, African Americans, and Hispanics using data from the 1989 National Medical Expenditure Survey (NMES). In 1989, the total national ED expenditures were $\$ 8.9$ billion, which represented $1.9 \%$ of the US total heath care spending. Private insurance paid $42 \%$ of the ED cost, Medicaid paid 13\%, Medicare paid $9 \%$, third party payees paid $19 \%$, and patients paid $19 \%$ out-of-pocket. The uninsured paid more of the ED cost out-of-pocket than the insured by $47 \%$ to $15 \%$. Free care to patients unable to pay amounted to $\$ 187$ million and was only $2 \%$ of the total ED cost (Tyrance et al., 1996). The authors identified many non-financial barriers that obstructed access to primary care for the uninsured minorities and increased reliance on ED use. These barriers included (a) lack of primary care provider in the inner 
city, (b) inability of low-wage workers to take time off work, (c) real or perceived racial discrimination, (d) psychiatric comorbidity, and (e) language difficulty. Tyrance et al. (1996) concluded that the use of the ED for non-urgent visits was a failure of the current health care system to provide adequate primary health care for its uninsured. Health insurance reform could improve access to primary care for many and would be a major step in reducing the need for ED visits.

\section{Method}

The appropriate Human Subject-Institutional Review Boards approved this research. In this non-experimental survey study, a non-probability, purposive sampling of Hispanic mothers with at least one child was used. The voluntary group came from a geographic area with a large Hispanic population. The survey site was the waiting area of a rural county pediatric clinic. A bilingual research assistant facilitated obtaining the signed consent forms and distributing the surveys to the volunteering mothers. All materials were translated into Spanish and validated by a bilingual expert.

Subjects were surveyed over a 3-day period in April of 1999. The subjects $(n=45)$ were screened and only non-pregnant Hispanic mothers over 18 with children were invited to participate. The participants completed the survey within an average of 15 minutes on site. To insure the subjects' anonymity, identifying markers were not placed on the survey tool. A $\$ 10.00$ compensation was given to all subjects who signed a consent form and returned the survey. The completion of the survey was facilitated by a bilingual research assistant who could read, help fill out surveys, or entertain subjects' children on request. The research assistant was an important factor in allowing the study to be concluded within the planned time frame and what was considered to be a culturally sensitive, non-threatening, and non-biased fashion. 
The primary data were collected with a questionnaire adapted from a tool designed by Saint-Germain, Bassford, and Montano (1993) from University of Arizona (Appendix B). The director of the University of Arizona's Rural Health Office, Jean McClelland M.P.H., gave written permission to use the Saint-Germain et al. (1993) tool. The study's 18item survey questionnaire was divided into 7 areas of interest. The research questions 1 through 18 (Q1-Q18) used in this study assessed: (a) the number of children (Q1), (b) barriers (Q2 \&Q9), (c) cues to action (Q12 \& Q13), (d) subjects' knowledge (Q4, Q1 1, \& Q14), (e) satisfaction (Q7, Q8, Q15, Q16, \& Q17), (f) access (Q3, Q5, Q6, \& Q10), and (g) likelihood of action (Q18) (See tables A, B, C, D, E, F, \&G).

\section{$\underline{\text { Results }}$}

Forty-five Hispanic mothers $(n=45)$ signed the consent form and returned the survey. The family size of the sample was small. Survey Q1 revealed that $60 \%$ of the subjects had 2 or fewer children (Table A).

Survey Q2 and Q9 addressed barriers to health care (Table B). In Q2, 82\% of the mothers answered that they have not had any problems getting health care for their children. In Q9, the subjects could respond to 5 out of 16 choices of major barriers to health care for their children. The 3 most frequently marked barrier responses to health care in frequency percent were (a) too long of a wait $(55 \%)$, (b) do not have insurance (35.6\%), and (c) could not pay for the health care (28.9\%). Response choices that (a) the staff does not speak Spanish, (b) services too far from were I live, and (c) I do not have any problems at all were marked with a frequency percent of $22.2 \%$ each.

Survey Q12 and Q13 related to cues to action (Table C). The major influence on subjects using the hospital ED in Q12 were (a) family and friends (53.3\%), and (b) neighbors $(6.7 \%)$. The cue to action response, radio or television as an influencing force, 
was not chosen by any of the subjects. In Q13, family and friends (75.6\%) were the most significant cues to action to subjects about the presence of the county clinic.

Survey Q4, Q11, and Q14 assessed subjects' knowledge of available services (Table D). A majority of subjects (79\%) felt that the county clinics gave the best medical care (Q4). In Q11, the most marked reasons for deciding to go to the hospital ED were (a) the clinic is not open (62.2\%), (b) when I think it is an emergency (44.4\%), and (d) the ED is always open (31.1\%). When asked, who do you first go to with questions about your children's health care (Q14), the most common responses were (a) county clinics (55.6\%), (b) family or friends $(22.2 \%)$, and (c) the doctor $(17.8 \%)$.

Survey Q7, Q8, Q15, Q16 and Q17 assessed subjects' satisfaction (Table E). In Q7 and Q8, a majority of the subjects were either very satisfied or moderately satisfied with the health care they received at the clinic (81\%) and hospital ED (64.1\%). A large number of subjects (82\%) in Q15 felt that they were given adequate educational materials from the county clinics. Satisfaction was high (91\%) with the nurses and doctors answering questions in Q16. A high satisfaction rating was given (89\%) in Q17 for subjects feeling comfortable about asking questions of their health care professionals.

The theme of personal access was assessed in survey Q3, Q5, Q6, and Q10 (Table F). The county clinic (Q3) was the usual source of primary care for the subjects' children (84\%) compared to the hospital ED (12\%) and private doctors (9\%). Over $70 \%$ of the subjects had taken their children at least once to the hospital ED within the last year (Q5). However, $98 \%$ of the subjects had visited the county clinics with their children at least once and $17.8 \%$ had visited the clinic 10 or more times (Q6) within the last year. Survey Q10 asked what other health care agencies the subjects used for obtaining health care for their 
children. The most common replies were (a) the county clinics $(86.7 \%)$, (b) hospital ED in the area (44.4\%). (c) private doctor (20\%), and (d) hospital ED outside of the area (20\%).

Survey Q18 asked the subjects to mark 3 responses that would make health care for children in the area more accessible for others (Table G). The 5 most common responses were (a) shorter waiting time for appointments (88.9\%), (b) longer clinical hours and open 7 days a week (75.6\%), (c) shorter waiting time to see the doctor $(57.8 \%)$, (d) easier to get insurance for the children (28.9\%), and (e) better transportation to the clinic $(15.6 \%)$.

\section{Discussion}

The family size of the research study's subjects was small; $60 \%$ of the mothers had 2 children or fewer compared with an average of 5.7 children in other studies of Hispanic families (Zambrana et al., 1994). This could suggest that the mothers in this study are relatively young and just beginning to raise their families.

One of the surprising subject responses was that $82 \%$ of the mothers surveyed related that they had never had any trouble obtaining health care for their children. A possible explanation for this response is that this population is young and most or all of their children were born in local hospitals. After the child was born, the obstetrician would refer the mother and child to the county clinic to continue health care maintenance, where they would be covered under state supported insurance.

The most common perceived barriers to health care by the subjects, (a) too long of a wait, (b) don't have insurance, (c) could not pay for health care, (d) staff don't speak Spanish, and (e) services too far away from home, are common barriers described in other studies (Saint-Germain et al., 1993). By far, the most significant barrier to health care for this population is the waiting time for appointments and to see the provider. By placing more resources into speeding up appointments and reducing waiting time in clinic lobbies, utilization of clinic services for this population's children could be enhanced. 
The most important cues to action were family and friends. This is predicted by the HBM as major cues to action (Rosenstock, 1974). Media played little part in influencing the subjects to seek health care. The data demonstrate that word of mouth is a very strong force in this population. Information booths at local community, social, and religious events may be an effective tool for informing this population of the county clinic's services.

This population felt that the county clinics gave the best care by $79 \%$ and was the major source of medical information by $55.6 \%$. These responses are important when paired with the high satisfaction rating given both the county clinics ( $81 \%=$ frequency percent) and the local hospital ED (64.1\%). The participants in this study gave high marks on patient satisfaction to every survey question (Q7, Q8. Q15, Q16, and Q17). This population appears to feel good about the quality of care that the local providers can administer. Another reason for the high satisfaction could be attributed to the subjects' cultural custom of not wanting to offend any of the health care providers. In the literature review, many researchers have pointed out that subjects may answer surveys in ways they think will please and not offend health care professionals (Riportella-Miller et al., 1996).

Survey Q18 was designed to understand what barriers, if eliminated, would improve the likelihood of a health care action. The subjects in this research study responded with (a) shorter waiting times for appointments (88.9\%), (b) longer clinical hours (76.6\%), and (c) shorter waiting time to see the doctor (57.8\%). These answers agree with perceived barriers in Q9 and reasons for going to the hospital ED in Q11. The data suggest that long waiting periods for clinical appointments, limited clinical hours, and lengthy waiting room delays are the major perceived barriers by these Hispanic mothers. 


\section{Limitations of the Study}

The adapted Saint-Germain, Bassford, and Montano's survey tool lacks reliability and may need more clinical application to test its cultural sensitivity to subject satisfaction. The high marks for satisfaction could be compared with other tools in the future to validate its accuracy.

The apparent young sample population and small family size in this study make it difficult to generalize the findings. A larger sample population taken over a 6-day period might have changed the demographics.

The survey site was the waiting area of one children's clinic in central California. This site was chosen because of the positive support of the clinic's staff and management to allow the study to be conducted. It would have been interesting to do the same survey simultaneously in the local hospital ED lobby.

\section{Conclusion}

The high satisfaction for the health care services received and the impressive number of mothers not experiencing difficulty in obtaining health care at this location suggest a system that is working. Mothers giving birth to children in local hospitals appear to have fewer problems in accessing health care services at the county clinic and hospital ED. Problems areas do exist with long waiting periods for appointments, limited clinical hours, and long delays in the waiting room before seeing the health care provider.

Putting more clinic resources in speeding up appointment scheduling and reducing the time it take to register before seeing the provider would reduce major barriers for this population. Mailing notices of upcoming appointments may reduce the no-show rate of patients without phones. Improving communication and understanding between the local hospital ED providers and the county clinic in developing a fast track referral plan would aid 
in funneling patients back to the clinic from the ED. Advertising expanded clinical evening weekend hours in local papers and community events may improve clinic utilization.

Suggestions for further research would include a measure of social acceptability. What is an acceptable waiting time for appointments and delays in the clinic lobby before seeing a provider for this population? In the year 2000 , even people without insurance do not have time to wait for distant appointment dates and lengthy office visits. Interviewing Hispanic mothers at the local ED waiting room and local public venues would increase the population base for future research. Looking at perceived barriers between Hispanic mothers with children born outside of the USA and those with children born in local hospitals may reveal an important entry point for future education. 


\section{$\underline{\text { References }}$}

Chan, T., Krishel, S., Bramwell, K., \& Clark, R. (1996). Survey of illegal immigrants seen in an emergency department. Western Journal of Medicine, 164, 212-216.

Haggerty, R. (1995). Child health 2000: New pediatrics in the changing environment of children's needs in the $21^{\text {st }}$ century. Pediatrics, $96,804-812$.

Janz, N., \& Becker, M. (1984). The health belief model: A decade later. Health Education Quarterly, 11, (1) 1-46.

McCormack-Brown, K. (1999). The health belief model overview. [On-line]. Available: http://www. Med.usf.edu/ kmbrown/Health Belief Model Overveiw.htm

Riportella-Muller, R., Selby-Harrington, M., Richardson, L., Donat, P., Luchok, 1., \& Quade, D. (1996). Barriers to the use of preventive health care services for children. Public Health Reports, 111, 71-77.

Rosenstock, I. (1974). Historical origins of the health belief model. Health Education Monograms, 2, 328-335.

Saint-Germain, M., Bassford, T., \& Montano, G. (1993). Surveys and focus groups in health research with older Hispanic women. Qualitative Health Research, 3, 341-367.

Strecher, V., \& Rosenstock, I. (1997). The health belief model. In K. Glanz, F. Lewis, \& B. Rimer (Eds.), Health behavior and health education: Theory, research and practice, ( $2^{\text {nd }}$ ed., pp. 41-59). San Francisco: Jossey-Bass.

Tyrance, P., Himmelstein, D., \& Woolhandler, S. (1996). US emergency department costs: No emergency. Public Health Policy Forum, 86, 1527-1531.

U.S. Department of Health and Human Services. (1999). Hispanic customer services demographics [On-line]. Available: http://www.hhs.gov/about/hisp.html 
Zambrana, R., Ell, K., Dorrington, C., Wachsman, L., \& Hodge, D. (1994). The relationship between psychosocial status of immigrant Latino mothers and use of emergency pediatric services. National Association of Social Workers, 19, 93-103. 


\section{Tables A-G}

\section{Table A Number children (01)}

\begin{tabular}{|l|r|r|r|r|r|}
\hline Q1 & \# of children & Frequency & Percent & Valid Percent & Cumulative Percent \\
\hline & 1 & 12 & 26.7 & 26.7 & 26.7 \\
\hline & 2 & 15 & 33.3 & 33.3 & 60 \\
\hline & 3 & 6 & 13.3 & 13.3 & 73.3 \\
\hline & 4 & 6 & 13.3 & 13.3 & 86.7 \\
\hline & 5 & 3 & 6.7 & 6.7 & 93.3 \\
\hline & 6 & 1 & 2.2 & 2.2 & 95.6 \\
\hline & 7 & 1 & 2.2 & 2.2 & 97.8 \\
\hline & 9 & 1 & 2.2 & 2.2 & 100 \\
\hline
\end{tabular}

Table B Barriers to health care $(02 \& 09)$

Q2 Any problems getting health care for your children?

\begin{tabular}{|l|l|r|r|r|r|}
\hline Q2 & & Frequency & Percent & Valid Percent & Cumulative Percent \\
\hline Valid & Yes & 8 & 17.8 & 17.8 & 17.8 \\
\hline & No & 37 & 82.2 & 82.2 & 100 \\
\hline & Total & 45 & 100 & 100 & 100 \\
\hline
\end{tabular}

Q9 Select 5 problems you have had with getting health care for your children.

\begin{tabular}{|l|l|r|r|}
\hline Q9 & & Frequency & Percent \\
\hline & Too long of wait & 25 & 55.6 \\
\hline & $\begin{array}{l}\text { No Medical } \\
\text { Insurance }\end{array}$ & 16 & 35.6 \\
\hline & Cost too much & 13 & 28.9 \\
\hline & $\begin{array}{l}\text { They don't speak } \\
\text { Spanish }\end{array}$ & 10 & 22.2 \\
\hline & Too far away & 10 & 22.2 \\
\hline & $\begin{array}{l}\text { I have no } \\
\text { problems }\end{array}$ & 10 & 22.2 \\
\hline & I had to work & 9 & 20 \\
\hline
\end{tabular}




\section{Table C Cues to action (O12 \& 013$)$}

Q12 Who influences your decisions to go to hospital ED with your children?

\begin{tabular}{|l|l|r|r|r|r|}
\hline Q12 & & Frequency & Percent & Valid Percent & Cumulative Percent \\
\hline Valid & Family \& Friends & 16 & 35.6 & 53.3 & 53.3 \\
\hline & Neighbors & 2 & 4.4 & 6.7 & 60 \\
\hline & Por Inicative Propia & 12 & 26.7 & 40 & 100 \\
\hline & Total & 30 & 66.7 & 100 & \\
\hline & Missing & 15 & 33.3 & & \\
\hline & Total & 45 & 100 & & \\
\hline
\end{tabular}

Q13 How did you find out about the county clinic?

\begin{tabular}{|l|l|r|r|r|r|}
\hline Q13 & & Frequency & Percent & Valid Percent & Cumulative Percent \\
\hline Valid & Family \& Friends & 34 & 75.6 & 75.6 & 75.6 \\
\hline & By Doctor & 3 & 6.7 & 6.7 & 82.2 \\
\hline & Neighbors & 2 & 6.7 & 4.4 & 86.7 \\
\hline & By VMC Referral & 1 & 4.4 & 2.2 & 88.9 \\
\hline & By School & 1 & 2.2 & 2.2 & 91.1 \\
\hline & Other & 4 & 2.2 & 8.6 & 100 \\
\hline & Total & 45 & 100 & 100 & \\
\hline
\end{tabular}

Table D Subjects' knowledge $(04,011, \&$ O14)

Q4 Who gives the best medical care to your children?

\begin{tabular}{|l|l|r|r|r|r|}
\hline Q4 & & Frequency & Percent & Valid Percent & Cumulative Percent \\
\hline Valid & Hospital & 5 & 11.1 & 11.6 & 11.6 \\
\hline & VMC-County Clinic & 32 & 75.6 & 79.1 & 90.7 \\
\hline & Private Doctor & 4 & 8.9 & 9.3 & 100 \\
\hline & Total & 43 & 95.6 & 100 & \\
\hline & Missing & 2 & 4.4 & & \\
\hline & Total & 45 & 100 & & \\
\hline
\end{tabular}

Q11 Why do you decide to go to the hospital ED instead of the county clinic?

\begin{tabular}{|l|l|r|r|}
\hline Q11 & & Frequency & Percent \\
\hline & Clinic is not open & 28 & 62.2 \\
\hline & $\begin{array}{l}\text { When I think it is } \\
\text { and emergency }\end{array}$ & 20 & 44.4 \\
\hline & The ED is always & 14 & 31.1 \\
\hline
\end{tabular}




\begin{tabular}{|l|l|r|r|}
\hline & open & & \\
\hline & ED is quicker & 5 & 11.1 \\
\hline & $\begin{array}{l}\text { Insur. Covers ED } \\
\text { visit }\end{array}$ & 4 & 8.9 \\
\hline & More convenient & 3 & 6.7 \\
\hline & $\begin{array}{l}\text { Easier to get } \\
\text { transportation }\end{array}$ & 1 & 2.2 \\
\hline
\end{tabular}

Q14 When you have questions about health care for your children who do you go to firsts?

\begin{tabular}{|l|l|r|r|r|r|}
\hline Q14 & & Frequency & Percent & Valid Percent & Cumulative Percent \\
\hline Valid & Family \& Friends & 10 & 22.2 & 22.2 & 22.2 \\
\hline & VMC-Co. Clinics & 25 & 56.6 & 55.6 & 77.8 \\
\hline & Doctor & 8 & 17.8 & 17.8 & 95.6 \\
\hline & Hospital & 1 & 2.2 & 2.2 & 97.8 \\
\hline & Other & 1 & 2.2 & 2.2 & 100 \\
\hline & Total & 45 & 100 & 100 & \\
\hline
\end{tabular}

\section{Tables E Satisfaction $(07,08,015,016, \&$ Q17)}

Q7 How satisfied with the primary health care received at the county clinics?

\begin{tabular}{|l|l|r|r|r|r|}
\hline Q7 & & Frequency & Percent & Valid Percent & Cumulative Percent \\
\hline & VERY SATISFIED & 26 & 57.8 & 59.1 & 59.1 \\
\hline & MOD. SATISFIED & 10 & 22.2 & 22.7 & 81.8 \\
\hline & UNDECIDED & 7 & 15.6 & 15.9 & 97.7 \\
\hline & MOD. & 1 & 2.2 & 2.3 & 100 \\
\hline & DISSATISFIED & 44 & 97.8 & 100 & \\
\hline & Total & 1 & 2.2 & & \\
\hline & System & 45 & 100 & & \\
\hline & Total & \multicolumn{3}{l}{} \\
\hline
\end{tabular}

Q8 How satisfied with the primary health care received at the Hospital ED?

\begin{tabular}{|l|l|r|r|r|r|}
\hline Q8 & & Frequency & Percent & Valid Percent & Cumulative Percent \\
\hline & Very Satisfied & 14 & 31.1 & 35.9 & 35.9 \\
\hline & Mod. Satisfied & 11 & 24.4 & 28.2 & 64.1 \\
\hline & Undecided & 8 & 17.8 & 20.5 & 84.6 \\
\hline & Mod. Dissatisfied & 3 & 6.7 & 7.7 & 92.3 \\
\hline Very Dissatisfied & 3 & 6.7 & 7.7 & 100 \\
\hline Total & 39 & 86.7 & 100 & \\
\hline System & 6 & 13.3 & & \\
\hline Total & 45 & 100 & & \\
\hline
\end{tabular}


Q15 Did you receive adequate pediatric health care education materials at the county clinic?

\begin{tabular}{|l|l|r|r|r|r|}
\hline Q15 & & Frequency & Percent & Valid Percent & Cumulative Percent \\
\hline Valid & Yes & 36 & 80 & 81.8 & $\mathbf{8 1 . 8}$ \\
\hline & No & 8 & 17.8 & 18.2 & 100 \\
\hline & Total & 44 & 97.8 & 100 & \\
\hline & Missing & 1 & 2.2 & & \\
\hline & Total & 45 & 100 & & \\
\hline
\end{tabular}

Q16 Did a nurse or doctor answer questions that you had?

\begin{tabular}{|l|l|r|r|r|r|}
\hline Q16 & & Frequency & Percent & Valid Percent & Cumulative Percent \\
\hline Valid & Yes & 40 & 88.9 & 90.9 & 90.9 \\
\hline & No & 4 & 8.9 & 9.1 & 100 \\
\hline & Total & 44 & 97.8 & 100 & \\
\hline & Missing & 1 & 2.2 & & \\
\hline & Total & 45 & 100 & & \\
\hline
\end{tabular}

Q17 Did you feel comfortable asking questions?

\begin{tabular}{|l|l|r|r|r|r|}
\hline Q17 & & Frequency & Percent & Valid Percent & Cumulative Percent \\
\hline Valid & Yes & 39 & 86.7 & 88.6 & 88.6 \\
\hline & No & 5 & 11.1 & 11.4 & 100 \\
\hline & Total & 44 & 97.8 & 100 & \\
\hline & Missing & 1 & 2.2 & & \\
\hline & Total & 45 & 100 & & \\
\hline
\end{tabular}

$\underline{\text { Table F Access }(03,05,06, \& 010)}$

Q3 Where do you normally go for you children's health care?

\begin{tabular}{|l|l|r|r|r|r|}
\hline Q3 & & Frequency & Percent & Valid Percent & Cumulative Percent \\
\hline Valid & Hospitals & 4 & 8.9 & 8.9 & 8.9 \\
\hline & Private Doctors & 3 & 6.7 & 6.7 & 15.6 \\
\hline & Clinic & 38 & 84.4 & 84.4 & 100 \\
\hline & Total & 45 & 100 & 100 & \\
\hline
\end{tabular}


Q5 Time in the past year you have taken your children to the hospital ED?

\begin{tabular}{|l|l|r|r|r|r|}
\hline Q5 & & Frequency & Percent & Valid Percent & Cumulative Percent \\
\hline Valid & 0 & 14 & 31.1 & 32.6 & 32.6 \\
\hline & 1 & 8 & 17.8 & 18.6 & 51.2 \\
\hline & 2 & 7 & 15.6 & 16.3 & 67.4 \\
\hline & 3 & 7 & 15.6 & 16.3 & 83.7 \\
\hline & 4 & 4 & 8.9 & 9.3 & 93 \\
\hline & 5 & 1 & 2.2 & 2.3 & 95 \\
\hline & 10 & 2 & 4.4 & 4.7 & 100 \\
\hline & Total & 43 & 95.6 & 100 & \\
\hline & Missing & & & & \\
\hline & Total & & & & \\
\hline
\end{tabular}

Q6 How many times in the past year have you taken your children to the county clinic?

\begin{tabular}{|r|l|r|r|r|r|}
\hline Q6 & & Frequency & Percent & Valid Percent & Cumulative Percent \\
\hline & 0 & 1 & 2.2 & 2.2 & 2.2 \\
\hline & 1 & 7 & 15.6 & 15.6 & 17.8 \\
\hline 2 & 7 & 15.6 & 15.6 & 33.3 \\
\hline & 3 & 3 & 6.7 & 6.7 & 40 \\
\hline & 4 & 5 & 11.1 & 11.1 & 51.1 \\
\hline & 5 & 5 & 11.1 & 11.1 & 62.2 \\
\hline & 6 & 2 & 4.4 & 4.4 & 66.7 \\
\hline & 7 & 2 & 4.4 & 4.4 & 71.1 \\
\hline & 8 & 5 & 11.1 & 11.1 & 82.2 \\
\hline & 10 or more & 8 & 17.8 & 17.8 & 100 \\
\hline & Total & 45 & 100 & 100 & \\
\hline
\end{tabular}

Q10 Where have you taken your children for health care in the USA?

\begin{tabular}{|l|l|r|r|}
\hline Q10 & & Frequency & Percent \\
\hline & County clinics & 39 & 86.7 \\
\hline & Local hospital ED & 20 & 44.4 \\
\hline & Private Doctor & 9 & 20 \\
\hline & Other hosp. ED's & 9 & 20 \\
\hline & Pharmacy & 5 & 11.1 \\
\hline & $\begin{array}{l}\text { Curander or } \\
\text { Sabador }\end{array}$ & 0 & 0 \\
\hline
\end{tabular}




\section{Table G The likelihood of action (018)}

Q18 What 3 things would make primary pediatric health care more accessible for others?

\begin{tabular}{|l|l|l|l|r|}
\hline Q18A-I & \multicolumn{1}{|c|}{$\mid$} & Frequency \\
\hline Valid & \multicolumn{1}{|l|}{ A. Shorter waiting time for appointments } & & 40 \\
\hline & B. Shorter waiting time to see the Doctor & & 26 \\
\hline & C. Less paper work & & 6 \\
\hline & D. Clinic open longer hours and 7 days a week & 34 \\
\hline & E. Easier to get insurance for the children & & 73 \\
\hline & F. Better transportation to the Clinic & & 2 \\
\hline & G. More convenient location for the Clinic & & 5 \\
\hline & H. Friendlier staff at the Clinic & & 5 \\
\hline & I. Better Doctors at the Clinic & & & 140 \\
\hline
\end{tabular}




\section{Appendix A}

\section{The Health Belief Model}

\section{Individual Perceptions}

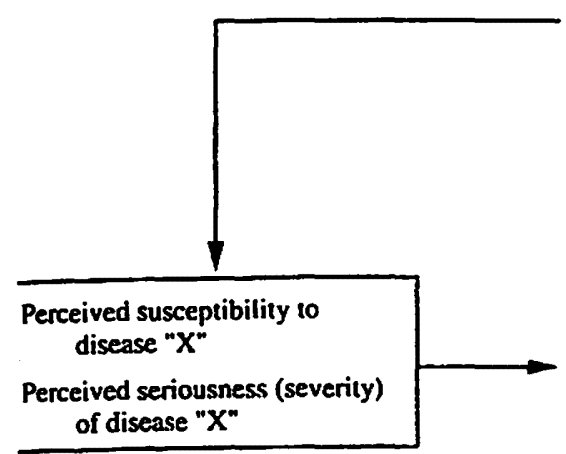

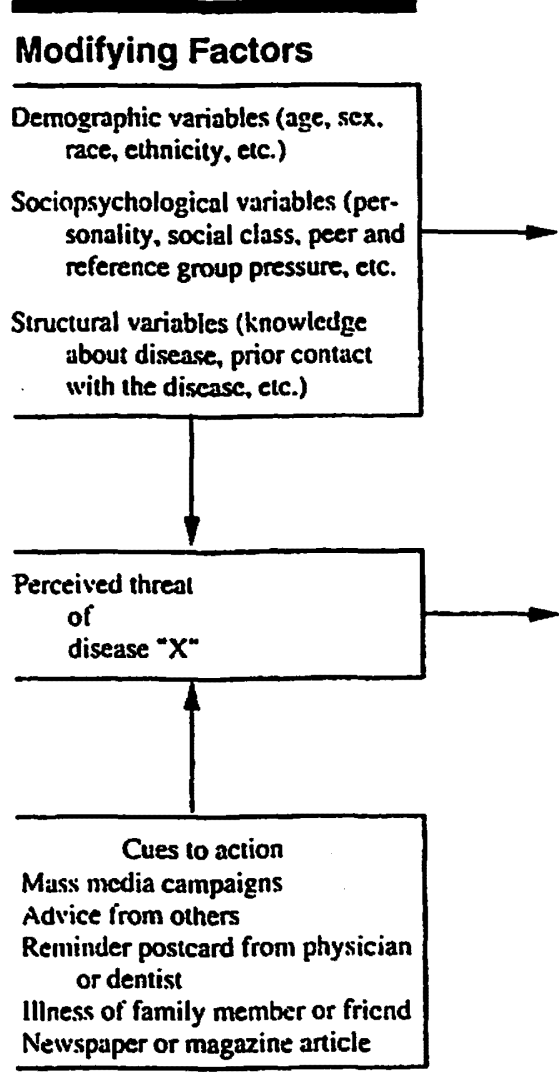

\section{Likelihood of Action}

Perceived benefits of preventive action

minus

Perceived barriers to preventive action

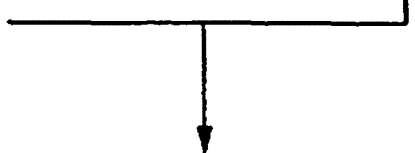

Likelihood of taking recommended preventive health action

Variables and relationships in the heafth belief model. (Redrawn from Rosenstock, I. M.: Historical origins of the health belief model. In Becker, M. H., ed.: The Health Belief Model and Personal Health Behavior. Thorofare, New Jersey: Charles B. Slack. 1974, pp. 1-8.) 


\section{Appendix B}

The 18 Item Tool for Access to Primary Health Care for Your Children

1. How many children do you have and what are their ages?
a. Numbers
b. Ages

2. Have you ever had any problems getting health care for your children?
a. Yes
b. No

3. Where do you normally go for your children's primary health care? (Mark only one)
a. Hospital
b. Private Doctor's office
c. Clinic

4. Who gives the best medical care to your children? (Mark only one)
a. Hospital
b. VMC-County Clinics
c. Private Doctor
d. Other

5. How many times in the last $\mathbf{1 2}$ months have you taken your children to the hospital emergency department?

$0-1-2-3-4-5-6-7-8-9-10$, or more.

6. How many times in the last $\mathbf{1 2}$ months have you taken your children to a county clinic?

$0-1-2-3-4-5-6-7-8-9-10$, or more.

7. How satisfied are you with the primary health care your children receive at the county clinics?
a. Very satisfied
b. Moderately satisfied
c. Undecided
d. Moderately dissatisfied
e. Very dissatisfied

8. How satisfied are you with the primary health care your children receive at the hospital emergency department?
a. Very satisfied
b. Moderately satisfied
c. Undecided
d. Moderately dissatisfied
e. Very dissatisfied 
9. From the list below, select up to 5 problems you have had with getting health care for your children?
a. Didn't know where to go.
b. Cost too much or couldn't pay for it.
c. Didn't have medical insurance.
d. They don't speak Spanish.
e. Medical services are far from where I live.
f. Didn't like the way I was treated last time.
g. Afraid they would find something wrong.
h. I had to work.
i. I would lose pay from work.
j. I would have to wait too long.
k. Afraid they would ask me to do something to my child that I did not want done (diet, surgery, immunization, hospital stay, etc.).
1. Lack of transportation.
m. The county clinic is not open when I need to see the doctor.
n. To much paper work to see the doctor.
o. I have not had any problems
p. Others (specify)

10. Where have you taken your children for health care in the USA? (Mark all that apply)
a. Curandero or Sobador
b. Pharmacy
c. Health Department Clinic/County Clinic
d. Private Doctor's office
e. Hospital ED in Gilroy
f. Hospital ED outside of Gilroy
g. Others (Specify)

11. Why do you decide to go to the hospital emergency department instead of the county clinic? (Mark all that apply)
a. The clinic is not open.
b. When I think it is an emergency.
c. When there was no time to go to the clinic.
d. It is quicker to go to the emergency department.
e. The health care is better.
f. Less paper work at the emergency department.
g. They treat the people better.
h. It is always open.
i. I can go when it is convenience to for me and my family.
j. It easier to get transportation to the emergency department.
k. Insurance will pay for the emergency department visit.

12. Who influences your decisions to go to the hospital emergency department for health care for your children? (Mark only one)
a. Television or radio
b. Family and friends
c. Neighbors 
13. How did you find out about the County Clinic?

(Mark only one)

a. Family or friends

d. Referred by doctor

e. Neighbors

f. Priest

g. Referred by VMC

h. Pharmacist

i. Radio or television

j. Referred by the school

k. Other (specify)

14. When you have questions about the health care of your children who do you go to first? (Mark only one)
a. Family or friends
b. Priest
c. VMC-County Clinic
d. Doctor
e. Hospital
f. Pharmacy
g. School
h. Other (Specify)

15. Did you receive adequate pediatric health care education materials when you visited the county clinic?
a. Yes
b. No

16. Did a nurse or doctor answer the questions you had?
a. Yes
b. No

17. Did you feel comfortable asking questions?
a. Yes
b. No

18. Mark the 3 things from the list below that you would like to see happen to make primary pediatric health care more accessible for others in this area?
a. Shorter waiting time for appointments
b. Shorter waiting time to see the doctor
c. Less paper work
d. The clinic open longer hours and 7 days a week
e. Easier to get insurance for the children
f. Better transportation to the clinic
g. More convenient location for the clinic
h. Friendlier staff at the clinic
i. Better doctors at the clinic 